\title{
La historia es de quien la trabaja. Documentos indígenas: una ventana al pasado
}

\author{
Leonardo Abraham González Morales
}

\begin{abstract}
Resumen
La opinión de la historia como materia aburrida puede ser distinta si se usan diversas posibilidades para conocer el pasado. Precisamente para romper esta tendencia, podríamos preguntarnos cómo podemos motivar el gusto por la historia. El presente texto explora una respuesta a esta interrogante mediante el estudio de los títulos primordiales de los pueblos indígenas. El artículo parte de un episodio poco conocido sobre la historia de Emiliano Zapata, en el que, antes de ser revolucionario, se aventuró a descifrar los títulos primordiales del pueblo de Anenecuilco. El ahondar en los títulos primordiales representan una valiosa oportunidad para explorar la memoria indígena como un cuerpo de creencias vivas y en contante transformación, muestra de que hay otras formas mirar la historia.
\end{abstract}

Palabras clave: títulos primordiales, indígena, códice, Zapata, derechos.

\section{HISTORY BELONGS TO THOSE WHO WORK IT. INDIGENOUS DOCUMENTS: A WINDOW TO THE PAST}

\begin{abstract}
The view of history as a boring class can change if other possibilities are explored in order to know the past. To break this trend, we could ask ourselves how we can motivate people to like history. This paper explores one answer to this question, through the study of primary titles of indigenous towns. The article begins with a little-known episode of Emiliano Zapata, in which, before becoming a revolutionary, he ventured to research the meaning of primary titles of Anenecuilco town. In this way, primary titles are a valuable opportunity to explore indigenous memory as a body of living beliefs in constant transformation, showing that there are other ways to look at history.
\end{abstract}

Keywords: primary titles, indigenous people, codex, rights, Zapata.

Recepción: 29/08/2019. Aprobación: 24/07/2020. Dol: http://doi.org/10.22201/cuaieed.16076079e.2020.21.6.2 
Es profesor de asignatura en la Academia de Ciencias Sociales e Historia, del Colegio de Bachilleres de la Ciudad de México. Realizó sus estudios profesionales y de posgrado en la UNAM, en el área de Humanidades. Destaca su amplia formación en la investigación histórica en temas como la cartografía indígena y colonial, y en la docencia de Historia Universal y de México. Actualmente está incubando un emprendimiento educativo de base tecnológica y con impacto social, en la Coordinación de Innovación y Desarrollo de la unam. Cabe destacar que posee un gran interés por la historia de la ciencia y la tecnología, así como por la literatura y la filmografía medieval.

"Y ciertas cosas que no deberían haber sido olvidadas se perdieron. La historia se convirtió en leyenda, la leyenda se convirtió en mito"

J. R. R. Tolkien, El señor de los anillos.

\section{¿Para qué enseñamos historia?}

La respuesta a esta pregunta ha inspirado tesis, libros y artículos para justificar la obligatoriedad de la materia en el mapa curricular, aunque sólo los necios dudan sobre la necesidad de su enseñanza. La problemática no es el para qué, sino el cómo la enseñamos. En teoría, el conocimiento histórico tiene nuevas opciones con la era digital y las nuevas pedagogías; sin embargo, aún hay quienes siguen enseñando de forma enciclopédica y memorística.

Por esta razón, me atrevo a proponer otro escenario para la enseñanza de la historia. Imaginemos una clase donde los alumnos se sientan comisionados de paz, con la tarea de diseñar estrategias para llegar a un acuerdo en un conflicto agrario. Así, en vez de rellenar páginas y páginas de un libro de texto, les indicamos que cada parte cuenta con sus títulos primordiales y, por lo tanto, la comisión debe estudiarlos. Seguramente se preguntarán: ¿qué es un título primordial? Se brindará la respuesta más adelante.

La curiosidad en los alumnos puede detonarse si los títulos primordiales tienen códices, ya que suelen atrapar la atención por su belleza y composición policromática. De esta forma, la formulación de estrategias de paz los lleva a estudiar los documentos. Es una oportunidad para poner en juego la creatividad y el análisis crítico, así como el conocimiento de un pasado, sin lugar a duda, poco estudiado en nuestro país.

En México, cientos de pueblos se encuentran en serios conflictos agrarios que requieren el estudio de la historia por varias razones. Una de ellas es la importancia que tienen los títulos primordiales como testimonios de sus derechos agrarios. Emiliano Zapata, Caudillo del sur y líder revolucionario del Ejército del sur, lo vivió en carne propia. 
Imagen 1. Códice Azcatitlan,

fol. 29. 37 folios. Papel europeo, $21 \times 28 \mathrm{~cm} .1530$. Biblioteca Nacional de Francia. Biblioteca

Digital Mundial. Recuperado de https://www.wdl.org/ es/item/15280/ (Recursos

Educativos Abiertos de la unEsCO desde 2012)

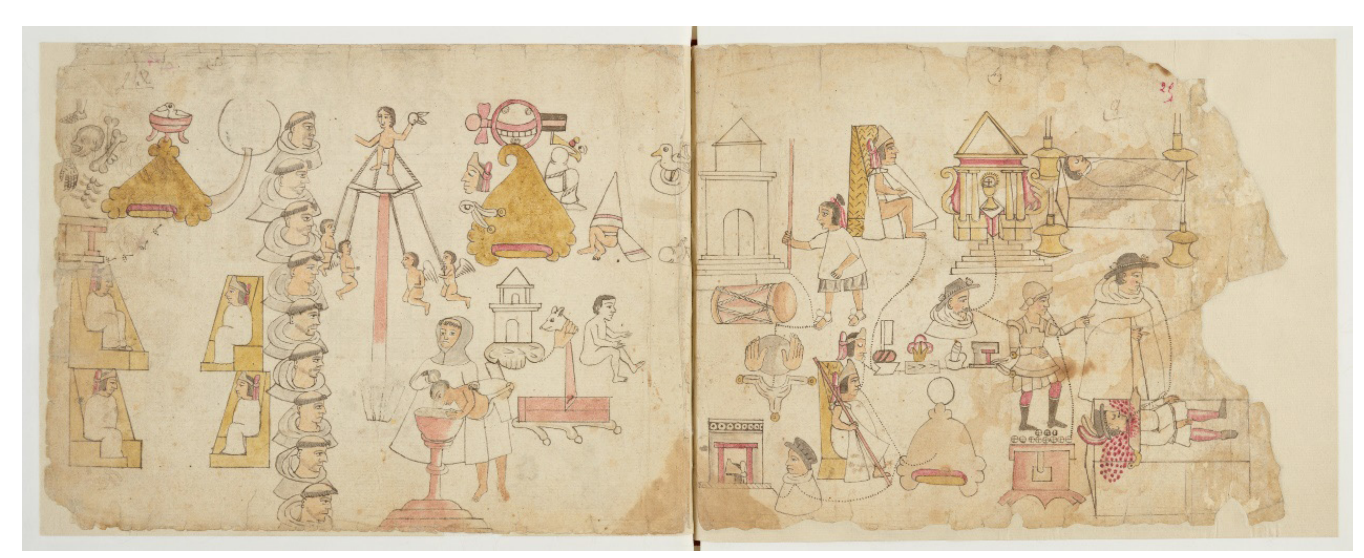

Los pobladores de Anenecuilco, su pueblo natal, vivieron una serie de profundos cambios políticos, legales, económicos, sociales y culturales después de la Independencia de México. Sin embargo, el más difícil fue hacia el último tercio del siglo xIx, cuando los gobiernos liberales en colusión con hacendados cañeros comenzaron un acoso sistemático para apoderarse de las tierras comunales. Para hacer frente a los abusos causados por la corrupción, los pobladores decidieron organizarse y renovar su oposición, al depositar el espíritu de lucha en los más jóvenes. Uno de ellos fue Emiliano Zapata, nombrado albacea de los títulos primordiales del pueblo.

La búsqueda de Zapata para descifrar el significado de los títulos se cuenta en la primera parte de este artículo. Después, se retoma la influencia de su lucha en la restitución de tierras de la Reforma agraria y la problemática emergente. El texto cierra con un catálogo sobre los títulos primordiales y su revaloración como fuentes de la historia, a partir de los estudios multidisciplinarios de finales del siglo xx. De esta forma, se intentará mostrar otra mirada hacia el pasado a través de la memoria indígena.

\section{Los títulos primordiales}

Cuando Emiliano Zapata fue nombrado albacea de los títulos primordiales de Anenecuilco, recibió un juego de documentos viejos, algunos mucho más que otros. Entre esos documentos había manuscritos en español y un mapa muy pintoresco con leyendas en idioma azteca, algo parecido a los jeroglíficos. ¿Por qué algunas veces se referían a ellos como jeroglíficos en idioma azteca? Porque su composición estética contiene pictografías, es decir, una forma de escritura que emplea representaciones simbólicas como figuras y dibujos. Uno de los ejemplos más bellos es el Códice Azcatitlán (Imagen 1), fuente colonial que desde tiempo inmemorial ha motivado el estudio y comprensión del pasado de los pueblos indígenas.

Los documentos de Anenecuilco aún se mantienen en secreto y su exposición digital no parece tener fecha; sin embargo, algunos investigadores se han acercado a ellos para estudiar la lucha del Caudillo del sur (Hernández, 1993). Posiblemente, estos documentos comparten características visuales con el Códice del 
Imagen 2. Códice del Marquesado del Valle, página 33. 28 hojas sueltas de gran formato, con pinturas y texto en náhuatl escrito con caracteres latinos. 1550 - 1560 Biblioteca Nacional de Francia. Biblioteca Digital Mundial. Recuperado de https://www.wdl.org/es/ item/9681/view/1/33/. (Recursos Educativos Abiertos de la unESCO desde 2012).
Marquesado del Valle (Imagen 2), tales como la mezcla de elementos pictográficos con caracteres latinos para expresar palabras en español o náhuatl. Además, este códice también fue empleado por algunos pueblos del actual estado Morelos contra la usurpación de tierras e ingenios cañeros desde el siglo xvı.

La necesidad de conocer el significado de dichos documentos motivó a Zapata a peregrinar por Morelos, ya que en el pueblo ese conocimiento se había olvidado. Visitó varios lugares donde aún se hablaba náhuatl, aunque el resultado fue poco alentador. Finalmente, sólo encontró a un cura que le ayudó a identificar algunos nombres (Krause, 1987).

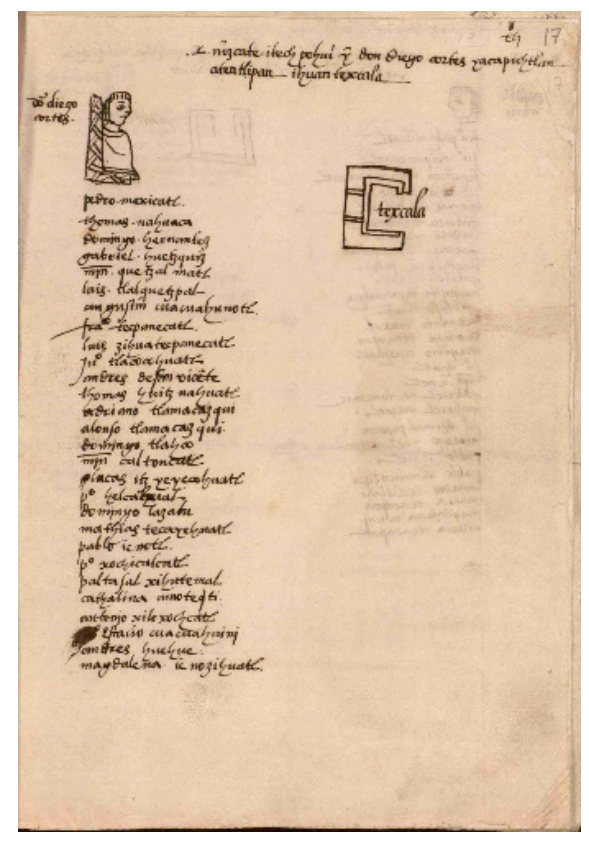

El regreso de este peregrinaje estuvo marcado por el aumento de las tensiones entre los pobladores de la región: hacendados y autoridades gubernamentales, que detonaron la violencia. Ante ello, Zapata y sus allegados iniciaron un movimiento revolucionario que interrumpió la búsqueda del significado de los títulos. Un siglo ha transcurrido y aún sabemos poco de esos documentos. Sin embargo, la inquietud de Zapata es algo que podemos plantearnos en estas preguntas: ¿qué son los títulos primordiales?, ¿quiénes los hacían?, ¿cómo se heredaban? y ¿por qué se fue olvidando su significado?

A finales del siglo xIx, un número importante de pueblos aún hablaba náhuatl dentro de México. En la mayoría de ellos, la lengua continuó en su tradición oral, adaptándose a los profundos procesos de cambio como la Conquista, la Colonia española, la Independencia y la modernización. Sin embargo, la escritura del náhuatl y la pintura de códices habían quedado en el olvido desde mucho tiempo atrás.

El arte de pintar códices se remonta a la época prehispánica y sólo se enseñaba a una élite. Como la mayoría de las pinturas estaban relacionadas con las creencias y prácticas religiosas, al concluir la Conquista, los españoles y la iglesia católica condenaron e intentaron eliminar todo rastro de ellas. Hacia finales del siglo xvi, casi todos los libros de pinturas habían sido quemados y los sabios-artistas prácticamente se habían extinguido.

Algunos aprendices sobrevivientes, herederos de la élite de las familias gobernantes, así como frailes, intentaron rescatar algunas tradiciones mediante negociaciones culturales. La pintura de códices fue una de ellas, aunque la mezcla de elementos prehispánicos y españoles fue inevitable. Al principio, algunos pueblos aprovecharon el intercambio cultural e intentaron defender sus derechos de tierras mediante testimonios orales. Después, agregaron documentos donde adaptaron la mezcla de elementos prehispánicos y españoles.

Catalogamos el resultado como documentos coloniales híbridos, porque mezclan varios elementos lingüísticos y jurídicos. Ejemplo de ellos son códices, mapas, planos, narrativas en español y en lenguas locales con letras del latín, 
líneas genealógicas, íconos cristianos, colores, firmas y sellos. Algunos trabajos fueron elaborados por tlacuilos.

Los pueblos conservaron estos documentos porque las autoridades reales o eclesiásticas los aceptaron como testimonios de sus derechos. Desde entonces, los custodiaron como títulos primordiales, es decir, los primeros títulos escritos en los que constan sus derechos. Los documentos podían ser custodiados por la iglesia local, el palacio del gobierno local o mediante albaceas.

La custodia continuó por siglos, aunque la comprensión de los documentos se fue olvidando. Dos de las causas fueron la extinción de los tlacuilos y la adopción del español como lengua principal o "civilizatoria". Por ello, la generación de Zapata desconocía las leyendas aztecas. Cabe mencionar que algunos aficionados, historiadores, anticuarios e intelectuales modernos, intentaron estudiar los "jeroglíficos mexicanos", aunque su mirada y esfuerzo estaban encaminados al campo académico y el coleccionismo.

\section{La caja de Pandora}

Inició la Reforma agraria, impulsada por los gobiernos de los caudillos revolucionarios. En el discurso político, la reforma representaba el triunfo de la lucha armada y los ecos de la justicia social. Uno de ellos fue la restitución de tierras, tema fundamental en la lucha revolucionaria, que quedó plasmado en el artículo 27 de la Constitución de 1917. Una victoria pírrica para el Ejército del sur.

La implementación de la reforma tuvo varios mecanismos de reparación de "justicia". Por ejemplo, se creó la colectivización de la tierra, el sistema ejidal y la organización de instituciones crediticias para el campo. Sin embargo, entre 1930 y 1970, estos procesos demostraron ser sumamente complejos y no estuvieron exentos de polémicas sobre favoritismos, clientelismo político, corrupción o proselitismo.

La restitución de tierras fue un tema aparte. Consistía en la revaloración de los derechos de un pueblo para devolverle aquello de lo que fue despojado de forma "injusta" hasta antes de la lucha armada. Por supuesto que la cantidad de injusticias cometidas habían sido incalculables, por lo tanto, se pidió el soporte documental necesario para reparar el daño. Es entonces que los pueblos sacaron sus títulos primordiales y comenzaron otra lucha: la de los tribunales.

La cantidad de casos desbordó la capacidad de los tribuales, pues no contaban con los recursos necesarios para interpretar los títulos primordiales. Se pidió ayuda a académicos, bibliotecarios y archiveros, pero la cantidad y la variedad de documentos hizo imposible la tarea. El resultado fue una problemática que avivó viejos y creó nuevos conflictos agrarios. Fue como abrir la caja de Pandora. ${ }^{2}$ 


\section{¿Cómo es que los títulos primordiales contienen los derechos de un pueblo?}

El contenido de los títulos primordiales es muy variado y su legitimidad depende de múltiples factores. En general, un documento es legítimo cuando un gobierno lo expide o lo acepta como testimonio y lo valida mediante firmas, sellos, marcas de autenticidad, etcétera.

Sin embargo, el caso de México es complejo porque el proceso de Independencia y las constantes guerras en el siglo xix causaron estragos en los archivos coloniales. Muchos documentos se perdieron o terminaron presas de saqueos o en colecciones privadas o en el extranjero. Por lo tanto, sólo se cuenta con copias o referencias secundarias.

Además, las grandes áreas del territorio mexicano que fueron sometidas a la modernización político-económica sufrieron transformaciones profundas, al pasar de paisajes de tierras comunales a fincas, haciendas, fábricas, vías de comunicación, tiraderos o drenajes. De esta forma, la dinámica capitalista desplazó a la vieja economía colonial y las leyes modernas socavaron la validez de los documentos coloniales híbridos, en gran medida porque sus jeroglíficos (códices) no se podían descifrar o eran inconmensurables con el sistema métrico decimal (Vera y García, 2011).

A pesar de ello, los pobladores de Anenecuilco, como muchos pueblos y barrios de origen indígena, transmitieron, mediante la tradición oral, la creencia de que sus derechos se encontraban depositados en los títulos primordiales. Además, durante siglos rememoraron sus derechos mediante prácticas agrarias, el marcaje de límites territoriales, la organización del riego, fiestas patronales, ritos religiosos y mayordomías. Por estas razones, la restitución de tierras representaba una valiosa oportunidad de refrendar derechos inmemoriales, es decir, de tiempos muy antiguos. La problemática y la falta de recursos llevaron a simplificar el reconocimiento de títulos primordiales: se catalogaron conforme al conflicto, se recogieron y enviaron a un archivo gubernamental, se registró la querella y la resolución del conflicto se dejó en manos de los técnicos, quienes intentaron hacer repartos de tierras "equitativos".

La restitución se convirtió en un discurso político lejos de la realidad agraria, pues para jueces y legistas resultaba imposible trasladar o traducir los títulos e interpretarlos en el marco de la ley moderna. Tal vez, esta sea la razón por la que este episodio no viene en los libros de historia, pues representa un fracaso revolucionario o una medida contraproducente.

\section{Una nueva esperanza}

Entre el siglo xIx y el xx, algunos códices fueron estudiados y descifrados desde la historia del arte. Sin embargo, esta misma curiosidad estética 
que despertaron entre intelectuales fue la causa principal de su peregrinaje a destinos desconocidos: incluso algunos aún se encuentran "desaparecidos". Por esta razón, hay títulos primordiales en colecciones privadas y en el extranjero (Noguez, 2017).

El gobierno mexicano custodia aquellos títulos que fueron enviados a los archivos, aunque, están desperdigados en varias dependencias. Algunos se encuentran en el Archivo General de la Nación, otros en el Archivo Histórico del Agua o en el Archivo de la Reforma Agraria. Otro problema es que no todos están catalogados, lo que dificulta su localización. Tal vez, en un futuro no muy lejano, se pueda acceder a ellos en plataformas como la Biblioteca Digital Mundial, la Biblioteca Digital Mexicana o el Archivo de Indias de Sevilla.

Aunque la presentación de títulos primordiales a tribunales tiene siglos, la encomienda de descifrar su significado e interpretar su contenido en el marco de las leyes modernas comenzó a finales del siglo xx, gracias a un grupo de expertos que retomó los conflictos agrarios mediante estudios multidisciplinarios (Mohar, 1994; Oudijk y Romero, 2003; Ruiz, Barrera y Barrera, 2012).

El significado del contenido de los títulos primordiales requiere de disciplinas como la historia, la jurisprudencia, la arqueología, la antropología, la etnología, la lingüística, la matemática, la cartografía, por mencionar algunas. También necesita de técnicas como la paleografía y la traductología, entre otras.

Asimismo, deben considerarse la peregrinación y los propósitos. La peregrinación es el recorrido que un título ha tenido, desde su elaboración hasta su localización actual. Algunos se mantuvieron en el mismo lugar, aunque su contenido sufrió modificaciones. Otros cambiaron de propósito, por ejemplo, hay documentos coloniales híbridos que se adaptaron a las Relaciones Geográficas enviadas a la corona española (Mundy, 2000). Por estas razones, el significado, la peregrinación y los propósitos de los títulos primordiales muestran la capacidad de la memoria indígena para adaptarse a los cambios. Podemos llamar a este fenómeno la circulación metamórfica del significado en la memoria de los pueblos.

La nueva ola de investigaciones multidisciplinarias renovó el interés en los títulos primordiales, convirtiéndolos en una valiosa, y poco explorada hasta ahora, fuente para el estudio de la historia. Además, estos estudios han impulsado la revisión y la conformación de comisiones de paz para los conflictos agrarios. A continuación, en la tabla 1, se proporciona un breve catálogo de documentos coloniales híbridos que pueden formar parte de los títulos primordiales de un pueblo. 
Tabla 1. Catálogo de documentos coloniales híbridos que pueden formar parte de los títulos primordiales.

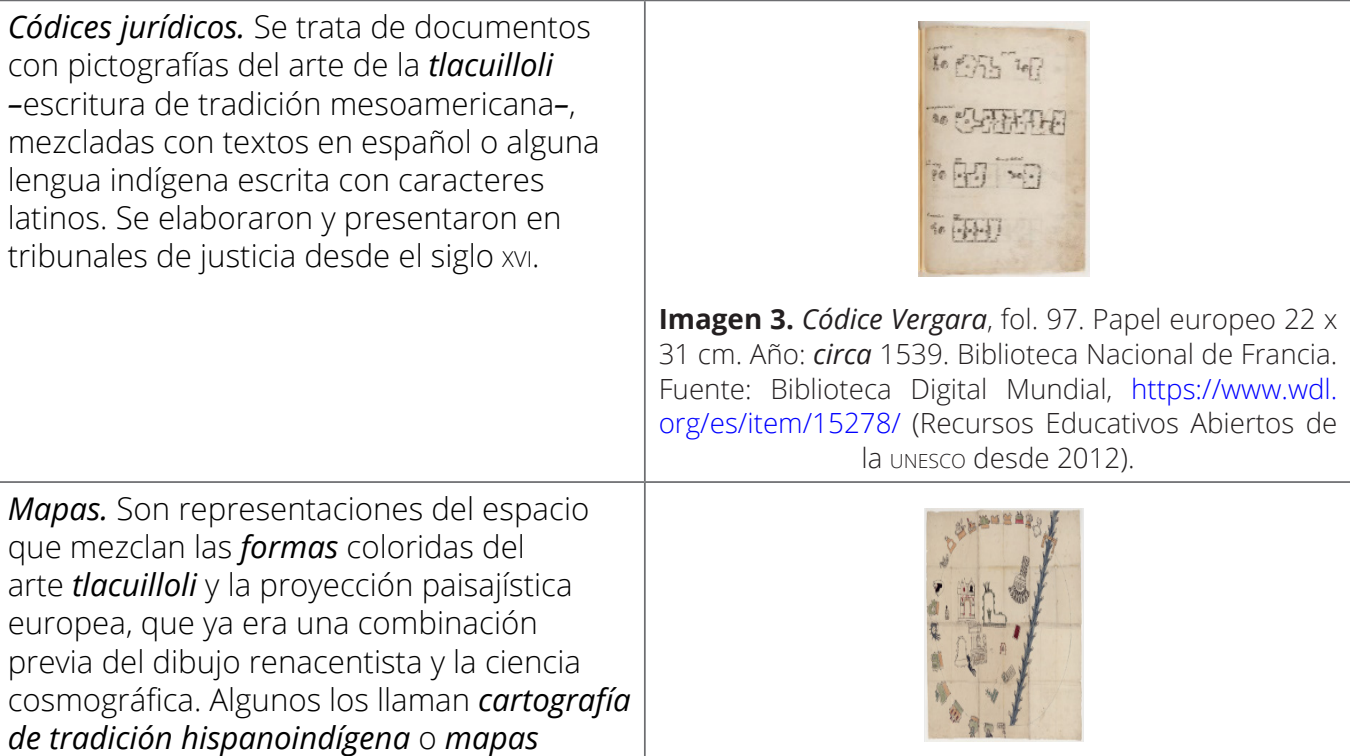
códices.

Imagen 4. Mapa de Amoltepec, 1 hoja. Papel europeo $30 \times 32$ cm. Año: 1580. Biblioteca de Austin Universidad. Biblioteca Digital Mexicana A. C. Recuperado de http://bdmx.mx/documento/galeria/mapa-relaciongeografica-amoltepec-1580 (Recursos Educativos Abiertos de la unesco desde 2012).

Relaciones geográficas. En un principio fueron representaciones geográficas y descripciones escritas del territorio colonial en América, elaboradas para el Rey Felipe II, en la segunda mitad del siglo xvı. En su hechura participaron algunos indígenas. Con el paso del tiempo, ciertos pueblos convirtieron las relaciones en testimonios legales.

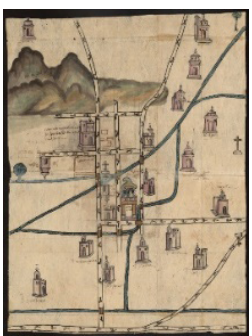

Imagen 5. Mapa de Culhuacán, 1 hoja, 1 folio, papel europeo 70 ×54cm. Año: 1580. Biblioteca de la Universidad de Texas. Biblioteca Digital Mundial Recuperado de https:// www.wdl.org/es/item/457/view/1/1/ (Recursos Educativos Abiertos de la unEsco desde 2012).

Techialoyan. Son un conjunto de códices producidos de forma genérica por un grupo de artesanos que conservaron algunas técnicas de la vieja tolacuillii, a finales del siglo xvı y a lo largo del xvIII. La mayoría fueron elaborados en el centro de México y, a diferencia de otras tradiciones, es clara su intención por representar los linderos y la posesión de tierras. Además, contienen amplia información escrita en español, náhuatl u otras lenguas, con breves pasajes de historia, genealogías y heráldicas. También cuentan con firmas como elementos de autenticidad.

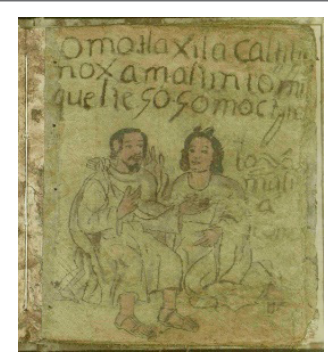

Imagen 6. Códice Techialoyan de Cuajimalpa, foja 23. Libro cosido de 26 fojas y un frontispicio. La primera y la última foja presentan faltantes. Circa 1680-1700. Archivo General de la Nación. Biblioteca Digital Mundial. Recuperado de https://www.wdl.org/es/item/9682/ (Recursos Educativos Abiertos de la unEsco desde 2012). 
Apócrifos. Son imitaciones modernas de las tradiciones artísticas indígenas. Se caracterizan por los rasgos toscos y las contradicciones en elementos como la temporalidad, los personajes, la historicidad, entre otros. Resalta el caso de Manuel Ramírez Arellano, un conocido falsificador y estafador dedicado a elaborar títulos apócrifos. Las falsificaciones fueron identificadas por Tomás Alarcón, jefe de paleografía de la Comisión Nacional Agraria. Entre los documentos apócrifos de Manuel Ramírez está el Lienzo del Pueblo de Santo Tomás Ajusco (Tlalpan, Ciudad de México).

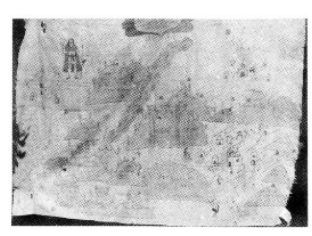

Imagen 7. Lienzo del pueblo de Santo Tomás Ajusco, 1 pieza en piel de venado. Circa 1890-1910. Recuperado de https://books.openedition.org/cemca/docannexe/ image/3350/img-16.jpg

\section{Memoria Viva}

A manera de reflexión final quisiera exponer tres puntos. Primero, los títulos primordiales son una valiosa oportunidad para conocer y dialogar con la memoria de los pueblos. Son otra ventana para explorar el pasado y plantear nuevas interrogantes a realidades que necesitamos comprender.

Segundo, el movimiento revolucionario encabezado por Emiliano Zapata motivó una reparación de justicia hacia los pueblos del país, primordialmente, mediante la restitución de tierras. Aunque esta preocupación llegó a ser parte de la Constitución de 1917 y de los mecanismos de reparación de justicia de la Reforma agraria, su implementación se convirtió en una caja de Pandora, ya que detonó numerosos conflictos agrarios y porque hicieron falta recursos para un mejor trabajo en los tribunales.

Tercero, después de siglos, los títulos primordiales fueron revalorados en el marco de sus tradiciones lingüísticas, gracias al trabajo multidisciplinario de varios expertos. A partir de entonces se estudian como nuevas fuentes para la historia. Uno de los descubrimientos más notables es el reconocimiento a la capacidad que tienen los pueblos para adaptarse a los cambios mediante el trabajo de su memoria.

Por estas razones, me atrevo a decir que la memoria de los pueblos de origen indígena es una memoria viva, opuesta a la historia oficial donde el pasado es inerte, lineal y "lejano", porque se trata de una memoria que nos enseña a explorar el pasado para defender el presente.

\section{Referencias}

* Acosta, V. y Vera, H. (cords.) (2011). Metros, leguas y mecates. Historia de los sistemas de medición. CIESAS-CIDESI. 
* González M., L. (2005). Los tlacuilos y la construcción del espacio novohispano en el siglo xvı. Revista Digital Universitaria, 16(4). http://www.revista.unam.mx/vol.16/ num4/art29/index.html

* Hernández, C. A. (1993). Anenecuilco memoria y vida de un pueblo. Fondo de Cultural Económica.

* Hinojosa H., Laura. (2014). Quince códices en la memoria de un convento. Los códices de Tlaquiltenango. INAH.

- Johansson, K. P. (2004). La palabra, la imagen y el manuscrito. Lecturas indígenas de un texto pictórico en el siglo XVI. UNAM.

* Krauze, E. (1987). Emiliano Zapata. El amor por la tierra. Fondo de Cultura Económica.

* León Portilla, M. (2013). Derechos, tierras y visión del mundo de los pueblos indígenas: en la cartografía e ilustraciones novohispanas del siglo XVI al siglo XVIII. Cámara de Diputados, LxI Legislatura.

* Montes de Oca Vega, M., Raby, D., Reyes Equiguas, S. y Sellen, A. T. (2003). Cartografía de tradición hispanoindígena. Mapas de mercedes de tierras, siglos XVI $y$ XVII. UNAM, 2 vols.

* Noguez, X. (coord.) (2017). Códices. Secretaría de Cultura.

- Oudijk, M. R. y Romero, A. M. (2003) Los títulos primordiales. Un género de tradición mesoamericana del mundo prehispánico al siglo xxı. Relaciones, xxIv(95), 18-48.

- Ruiz, E., Barrera, C. y Barrera F. (2012). La lucha por la tierra. Los títulos primordiales y los pueblos indios en México, siglos xix y xx. Fondo de Cultura Económica.

Tolkien, J. R. R. (1954). El señor de los anillos (Lluis Doménech y Matilde Horne, trads.). Planeta.

* Valbuena Briones, A. (1989). El mito de Pandora en Calderón. Thesaurus: Boletín del instituto Caro y Cuervo, 44(1), 64-82.

- Womack, J. (2017). Zapata y la Revolución mexicana (Francisco González Aramburo, trad.). Fondo de Cultura Económica.

\section{Cómo CITAR ESTE ARTículo}

* González Morales, Leonardo Abraham. (2020, noviembre-diciembre). La historia es de quien la trabaja. Documentos indígenas: una ventana al pasado. Revista Digital Universitaria (RDU), 21(6). Dol: http://doi.org/10.22201/ cuaieed.16076079e.2020.21.6.2 